\title{
Using spectral matched records to explore earthquake duration effect on inelastic response of structure
}

\author{
Hossein Bolboli ${ }^{*},{ }^{1}$, Abbas MaHdaVIAN ${ }^{2}$, Mohammad SAFI $^{3}$ \\ ${ }^{1}$ MSc Student, Faculty of Civil, Water and Environmental Engineering, Shahid Beheshti \\ University, Tehran, Iran \\ ${ }^{2}$ Associate Professor of Civil, Water and Environmental Engineering Faculty, Shahid \\ Beheshti University, Tehran, Iran \\ ${ }^{3}$ Assistant Professor of Civil, Water and Environmental Engineering Faculty, Shahid \\ Beheshti University, Tehran, Iran
}

\begin{abstract}
There are considerable debates in the technical literature regarding to effect of earthquake duration on damages in the structures. If duration of strong-motion is important, care must be taken that in design and evaluation of structures should be used records with suitable duration. In this study, time-history analysis has been done on an 8-story steel moment frame building using 49 accelerograms with different duration. Primary effect of earthquake spectral amplitude is homogenized by scaling and adjustment of records using wavelets so that they have good match to target smooth response spectrum of Iran seismic code. Comparing correlation between duration and different damage measures reveal that although duration has no important effect on maximum response measures, checking other measures show that structural damages may increases subjected to longer duration earthquake.
\end{abstract}

Key words: Accelerogram, Scaling, Earthquake duration, Time-history analysis, Damage measures

\section{Introduction}

Criteria in current seismic codes do not consider earthquake duration characteristic. Whilst there are many studies that directly and indirectly show correlation between earthquake duration and structural damages. For example Chai and co-workers (Refs [1,2]) suggest that inelastic design base shear should increase for buildings subjected to longer duration earthquake, while Iervolino et al. [3] and Shome et al. [4] find that earthquake magnitude and hence duration has no important effect on maximum inelastic displacement. Next studies support the policy in current seismic codes to ignore duration, whereas previous studies suggest that duration should be incorporated in seismic design criteria.

It is obvious that duration is secondary predictive parameters and to explore direct correlation between duration and damage would be futile. Another study by Bommer et al.

\footnotetext{
* Corresponding author: MSc Student

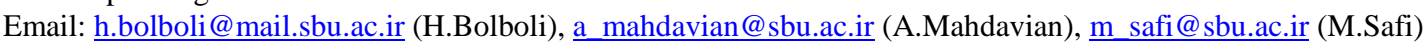


[5] using strength and stiffness degrading masonry structures demonstrates that for a given level of spectral acceleration, earthquake with longer duration caused more strength degradation than those with short duration.

In this study, an 8-story steel moment frame building is used to explore earthquake duration effect. Forty-nine records with duration between 5 to 40 seconds has been selected. Effect of two significant ground-motion characteristics i.e. peak ground acceleration (PGA) and frequency content is homogenized by adjustment and scaling of records using wavelets so that they have good match to the target spectrum. This ensures that the main difference between the accelerograms is the earthquake duration. Structure is modeled as a two-dimensional multi-degree-of-freedom considering nonlinearity in the geometry and materials. The influence of duration on different damage measures including maximum response measures, fatigue measures and energy measures is examined.

\section{Modeling}

In this paper, an 8-story special moment frame steel building designed based on Iran seismic code [6] (Fig. 1). Designed PGA is 0.35g. HEB and IPE is used for column and beam sections, respectively. All analyses were conducted using Perform 3D [7] that consider geometric non-linearity and material inelasticity. Structural members are modeled using ASCE41 [8].

\section{Damage Measures}

Conventional seismic design controls damages occur in the structure regarding to moderate and strong earthquakes. In addition, design philosophy requires a damage measure to quantify structural damage status. In many cases, the damage indices are dimensionless parameters ranging from zero to 1.0 for an undamaged structure to a collapsed structure. For example, Fajfar [9] suggests that the damage measure value between zero and 0.4 can be assumed as repairable whereas the damage measure value between 0.4 and 1.0 represents to the damage beyond repair.

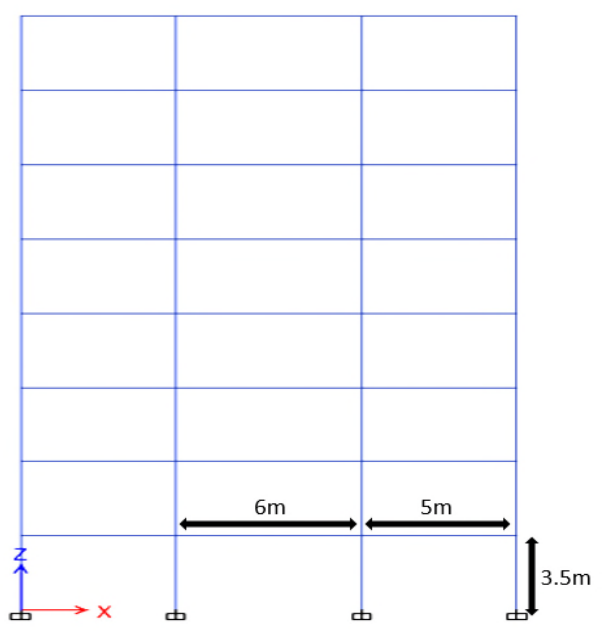

Figure 1: Built-in model in software

There are a wide range of damage index suggested in the literature that they can be divided into four main groups: 
1- Maximum response measures,

2- Fatigue measures,

3- Energy measures,

4- Measures using combination of the above mentioned indices.

Because of impossibility to use all of the proposed damage measures, at least one from each main group is used. For more detailed, the damage measures used in this study are:

$\checkmark$ peak roof drift,

$\checkmark$ peak inter-story drift, for all stories,

$\checkmark$ peak member end rotation,

$\checkmark$ member rotational fatigue,

$\checkmark$ absorbed hysteretic energy,

$\checkmark$ Park and Ang damage measure.

\section{Selected records}

Because of complexity of the records, it is important to use suitable ones. So different effects of ground motion, like frequency content, amplitude and site effects (near field) must be minimized. It helps to explore duration effect on the structure. For this purpose, following cases should be considered.

Selected records should be widespread enough to have sufficient records for long duration earthquake. It is significant, in the way that the number of strong earthquake and thus long duration records is low. Care must be taken to select records without near field pulse. In addition, Magnitude, distance to site, faulting mechanism and PGA are other important factors. Although, due to the lack of suitable records, this points cannot be considered suitably, and it is sufficient that collected records be extended within good range of duration. In Fig.2, effect of PGA on the ground motion duration is cleared for the collected records. It is obvious that PGA is decreased with increase in duration.

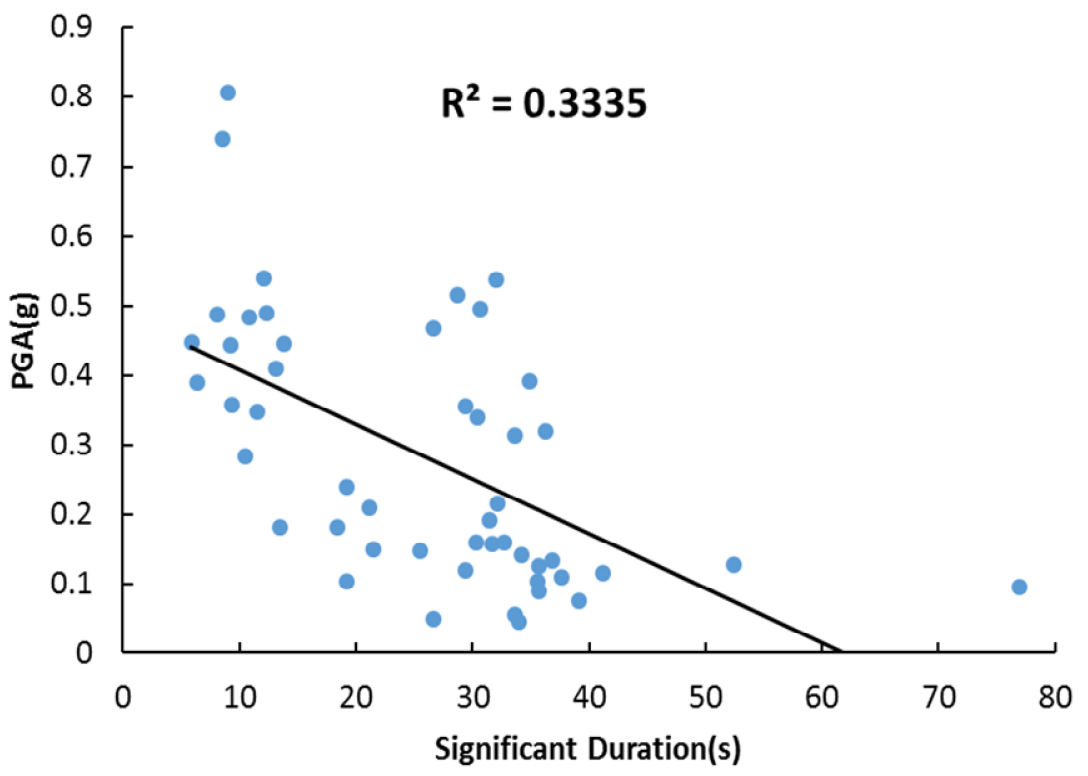

Figure 2: Magnitude vs. duration of earthquake

It is noted that total time of a record is not a scientific measurement of earthquake duration. This is because the overall length of an accelerogram can be so wide depending 
on the type of device records the ground motion. In addition, it is more important that only high amplitude section of a record may be the reason of inelastic behavior and damage in the structure.

Accordingly, there are more than thirty definition for quantifying earthquake duration for different purposes [5]. In this paper for measuring duration of ground motion significant duration taken into account. Significant duration is the interval of time over which a percentage of the total Arias Intensity is accumulated (default is the interval between the $5 \%$ and $95 \%$ thresholds). [10]

The total Arias Intensity is defined as:

$$
I_{A}=\frac{\pi}{2 g} \int_{0}^{t_{\max }} a^{2}(t) d t
$$

Where $\mathrm{a}(\mathrm{t})$ is acceleration and $\mathrm{t}_{\max }$ is total length of accelerogram.

Totally, according to what was said, suitable accelerograms were selected. In Table 1 selected records for time-history analysis are provided.

Table 1: Selected records and comparison before and after scaling

\begin{tabular}{|l|l|c|l|c|c|c|c|}
\hline \multirow{2}{*}{ Record ID } & \multirow{2}{*}{ Name } & Year & Station & \multicolumn{2}{|l|}{ Original Record } & \multicolumn{2}{l|}{ Adjusted Record } \\
\cline { 4 - 8 } & & & & PGA $(\mathrm{g})$ & SA $_{\text {RMS }}(\mathrm{g})$ & PGA $(\mathrm{g})$ & SA $_{\text {RMS }}(\mathrm{g})$ \\
\hline $510-1$ & Northridge & 1994 & Beverly Hills Mulhol & 0.49 & 0.31 & 0.43 & 0.01 \\
\hline $510-2$ & Northridge & 1994 & Canyon CountryWLC & 0.39 & 0.24 & 0.50 & 0.01 \\
\hline $510-3$ & Northridge & 1994 & Canyon CountryWLC & 0.45 & 0.24 & 0.46 & 0.01 \\
\hline $510-4$ & $\begin{array}{l}\text { Duzce, } \\
\text { Turkey }\end{array}$ & 1999 & Bolu & 0.74 & 0.31 & 0.53 & 0.01 \\
\hline $510-5$ & $\begin{array}{l}\text { Imperial } \\
\text { Valley }\end{array}$ & 1979 & El Centro Array\#11 & 0.36 & 0.30 & 0.42 & 0.02 \\
\hline $510-6$ & $\begin{array}{l}\text { Kocaeli, } \\
\text { Turkey }\end{array}$ & 1999 & Arcelik & 0.22 & 0.46 & 0.54 & 0.02 \\
\hline $510-7$ & Loma Prieta & 1989 & Gilroy Array \#3 & 0.35 & 0.26 & 0.39 & 0.01 \\
\hline $1015-1$ & Northridge & 1994 & Beverly Hills Mulhol & 0.44 & 0.22 & 0.36 & 0.02 \\
\hline $1015-2$ & Northridge & 1994 & Beverly Hills Mulhol & 0.81 & 0.26 & 0.51 & 0.01 \\
\hline $1015-3$ & Landers & 1992 & Coolwater & 0.28 & 0.35 & 0.45 & 0.02 \\
\hline $1015-4$ & Loma Prieta & 1989 & Capitola & 0.49 & 0.29 & 0.43 & 0.02 \\
\hline $1015-5$ & Superstition Hill & 1987 & Poe Road (temp) & 0.45 & 0.29 & 0.56 & 0.01 \\
\hline $1015-6$ & $\begin{array}{l}\text { Cape } \\
\text { Mendocino }\end{array}$ & 1992 & Rio Dell Overpass & 0.54 & 0.37 & 0.46 & 0.02 \\
\hline $1015-7$ & San Fernando & 1971 & $\begin{array}{l}\text { LA - Hollywood } \\
\text { Stor }\end{array}$ & 0.18 & 0.44 & 0.35 & 0.01 \\
\hline $1520-1$ & Bam & 2003 & Abaragh & 0.10 & 0.54 & 0.38 & 0.02 \\
\hline $1520-2$ & MANJIL & 1990 & Abhar & 0.21 & 0.30 & 0.31 & 0.02 \\
\hline $1520-3$ & MANJIL & 1990 & Qazvin & 0.18 & 0.41 & 0.39 & 0.01 \\
\hline $1520-4$ & Landers & 1992 & $\begin{array}{l}\text { Yermo Fire } \\
\text { Station }\end{array}$ & 0.24 & 0.29 & 0.41 & 0.01 \\
\hline $1520-5$ & Landers & 1992 & $\begin{array}{l}\text { Yermo Fire } \\
\text { Station }\end{array}$ & 0.15 & 0.37 & 0.41 & 0.03 \\
\hline $1520-6$ & Loma Prieta & 1989 & Capitola & 0.41 & 0.29 & 0.42 & 0.02 \\
\hline $1520-7$ & Chi-Chi & 1999 & TCU045 & 0.48 & 0.27 & 0.58 & 0.01 \\
\hline
\end{tabular}


Table 1: (cont.)

\begin{tabular}{|c|c|c|c|c|c|c|c|}
\hline \multirow{2}{*}{$\begin{array}{l}\text { Record } \\
\text { ID }\end{array}$} & \multirow{2}{*}{ Name } & \multirow{2}{*}{ Year } & \multirow{2}{*}{ Station } & \multicolumn{2}{|c|}{ Original Record } & \multicolumn{2}{|c|}{ Adjusted Record } \\
\hline & & & & PGA $(g)$ & $\mathrm{SA}_{\mathrm{RMS}}(\mathrm{g})$ & PGA(g) & $\mathrm{SA}_{\mathrm{RMS}}(\mathrm{g})$ \\
\hline $2025-1$ & Landers & 1992 & Amboy & 0.15 & 0.40 & 0.36 & 0.02 \\
\hline $2025-2$ & Landers & 1992 & Desert Hot Springs & 0.19 & 0.42 & 0.35 & 0.01 \\
\hline $2025-3$ & Tabas & 1978 & Deyhook & 0.31 & 0.36 & 0.34 & 0.01 \\
\hline $2025-4$ & Tabas & 1978 & Deyhook & 0.39 & 0.29 & 0.59 & 0.02 \\
\hline $2025-5$ & Kocaeli Turkey & 1999 & Bursa Sivil & 0.05 & 0.51 & 0.38 & 0.02 \\
\hline $2025-6$ & Chi-Chi & 1999 & HWA003 & 0.05 & 0.50 & 0.33 & 0.01 \\
\hline $2025-7$ & Chi-Chi & 1999 & CHY101 & 0.34 & 0.21 & 0.53 & 0.02 \\
\hline $2530-1$ & $\begin{array}{c}\text { Taiwan } \\
\text { SMART1(45) }\end{array}$ & 1986 & SMART1 O08 & 0.14 & 0.39 & 0.45 & 0.01 \\
\hline $2530-2$ & Landers & 1992 & Amboy & 0.12 & 0.43 & 0.31 & 0.01 \\
\hline $2530-3$ & Landers & 1992 & Desert Hot Springs & 0.16 & 0.40 & 0.47 & 0.02 \\
\hline $2530-4$ & Landers & 1992 & Coachella Canal & 0.10 & 0.46 & 0.33 & 0.01 \\
\hline $2530-5$ & Landers & 1992 & Palm Springs Airport & 0.09 & 0.45 & 0.49 & 0.01 \\
\hline $2530-6$ & Manjil & 1990 & Abbar & 0.52 & 0.30 & 0.43 & 0.01 \\
\hline $2530-7$ & Chi-Chi & 1999 & CHY101 & 0.47 & 0.13 & 0.43 & 0.02 \\
\hline $3035-1$ & Landers & 1992 & Mission C.F. & 0.13 & 0.48 & 0.36 & 0.02 \\
\hline $3035-2$ & Kocaeli & 1999 & Bursa Sivil & 0.05 & 0.50 & 0.40 & 0.01 \\
\hline $3035-3$ & Ardebil & 1997 & Ardebil & 0.16 & 0.45 & 0.47 & 0.01 \\
\hline $3035-4$ & Chile & 2010 & Llolleo & 0.32 & 0.31 & 0.38 & 0.01 \\
\hline $3035-5$ & Chile & 2010 & Llolleo & 0.54 & 0.34 & 0.42 & 0.02 \\
\hline $3035-6$ & Manjil & 1990 & Abbar & 0.50 & 0.23 & 0.44 & 0.02 \\
\hline $3035-7$ & $\begin{array}{l}\text { Superstition } \\
\text { Hills }\end{array}$ & 1987 & El Centro Imp. Co. & 0.36 & 0.26 & 0.47 & 0.01 \\
\hline $3540-1$ & Landers & 1992 & Indio-Coachella C. & 0.11 & 0.44 & 0.41 & 0.01 \\
\hline $3540-2$ & Landers & 1992 & Mission C.F. & 0.12 & 0.46 & 0.39 & 0.03 \\
\hline $3540-3$ & Landers & 1992 & Palm Springs Airport & 0.08 & 0.47 & 0.29 & 0.01 \\
\hline $3540-4$ & Ardebil & 1997 & Ardebil & 0.13 & 0.45 & 0.36 & 0.03 \\
\hline $3540-5$ & Kern County & 1952 & Taft Lincoln School & 0.16 & 0.42 & 0.50 & 0.02 \\
\hline $3540-6$ & Chi-Chi & 1999 & CHY004 & 0.09 & 0.47 & 0.43 & 0.01 \\
\hline $3540-7$ & Chi-Chi & 1999 & CHY008 & 0.13 & 0.41 & 0.43 & 0.01 \\
\hline
\end{tabular}

\section{Scaling and matching}

To minimize spectral amplitude effect in the results, all records are scaled to the target response spectrum using SeismoMatch [11].SeismoMatch uses wavelets to adjust accelerograms in the way that minimize changes in the other earthquake characteristics. The target spectrum can be gained from seismic hazard analysis. This spectrum is obtained using predictive equations for a specified magnitude, type of fault, distance to fault and site conditions [12]. However, the target spectrum in this paper is smooth spectrum of Iran seismic code [6] for soil type III and PGA is equal to $0.35 \mathrm{~g}$.

In Fig.3 and Fig.4 comparison between response spectrum of records and target spectrum are shown before and after matching them. As shown, the scaled accelerograms have a good match to the target spectrum. It means that amplitude and spectral shape effects are removed in the analysis and the only comparable characteristic between records is ground motion duration. 


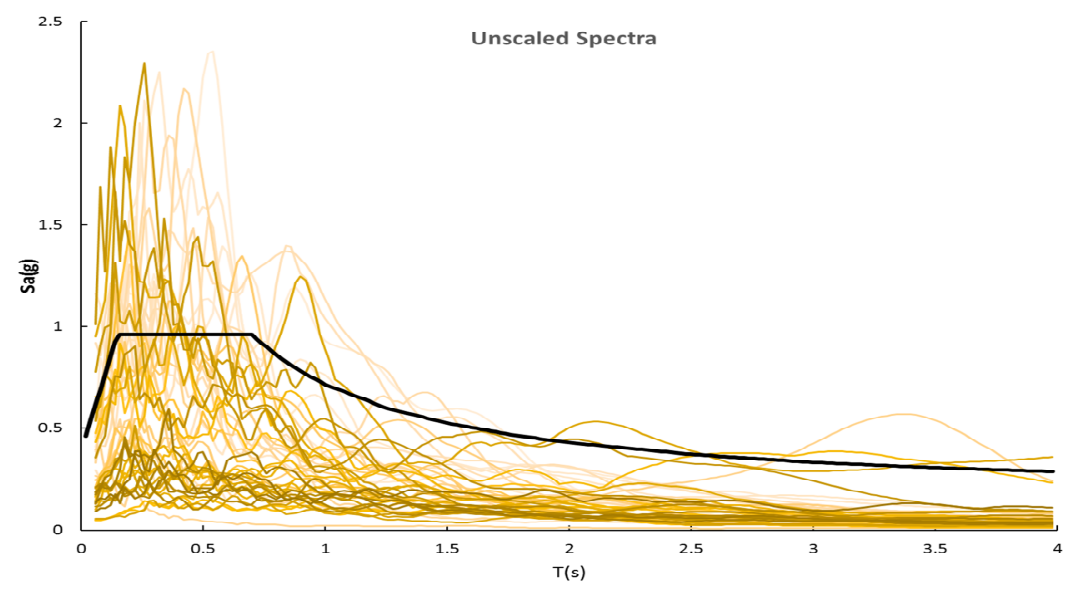

Figure 3: Acceleration response spectra for selected records before scaling

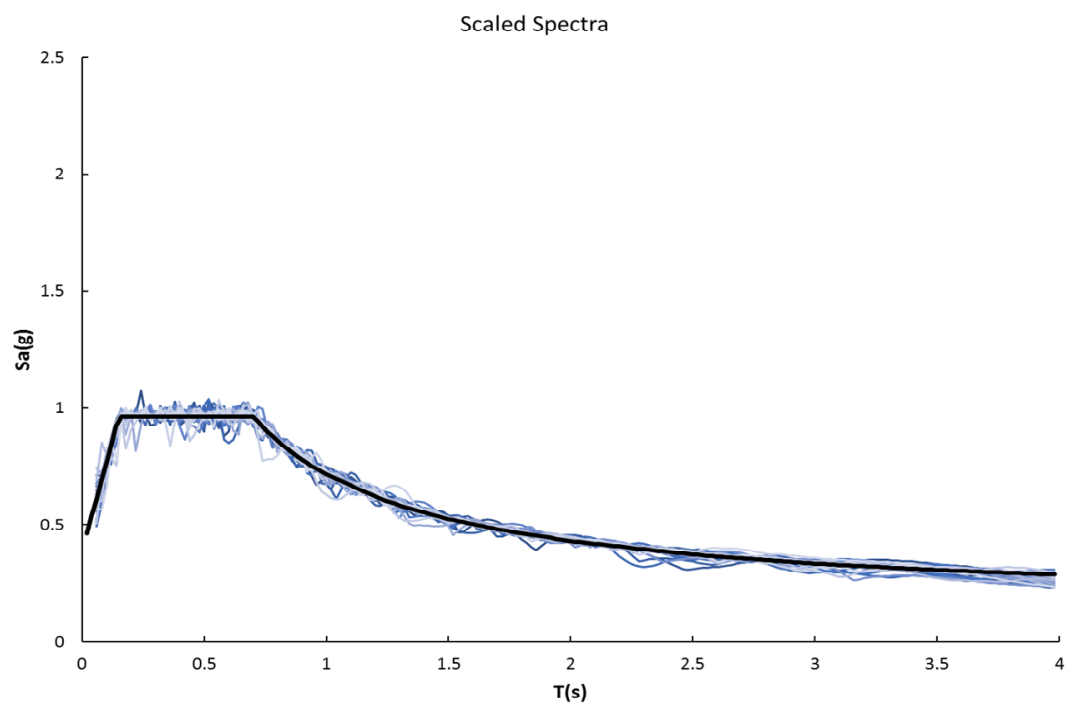

Figure 4: Acceleration response spectra for selected records after scaling

In order to have better comparison between target spectrum and adjusted spectra, the following root mean square of spectral acceleration ( $\left.\mathrm{SA}_{\mathrm{RMS}}\right)$ is defined:

$\mathrm{SA}_{\mathrm{RMS}}=\sqrt{\frac{1}{N} \sum_{i=1}^{N}\left[\mathrm{SA}_{\mathrm{O}}\left(T_{i}\right)-\mathrm{SA}_{\mathrm{S}}\left(T_{i}\right)\right]^{2}}$

In which $S A o\left(T_{i}\right)$ is spectral acceleration in period $T_{i}$ for the recorded ground motion, $S A_{S}\left(T_{i}\right)$ is target spectral acceleration and $N$ is the number of periods at which compatibility is examined.

According to definition in Eq. (2), a better compatibility for the adjusted record depends on a smaller $\mathrm{SA}_{\mathrm{RMS}}$ value. Table 1 shows $\mathrm{SA}_{\mathrm{RMS}}$ values for different earthquakes before and after scaling. As shown, a suitable compatibility is observed between target spectrum and all the adjusted records.

Although, abovementioned changes have been done in the ground motion record help earthquake duration to be the only variable of analysis, it is essential to compare duration 
values before and after adjustment. Fig. 5 compares earthquake duration values before and after adjustment. As shown, error values are low and it is not necessary to reset the records.

\section{Significant Duration(second)}

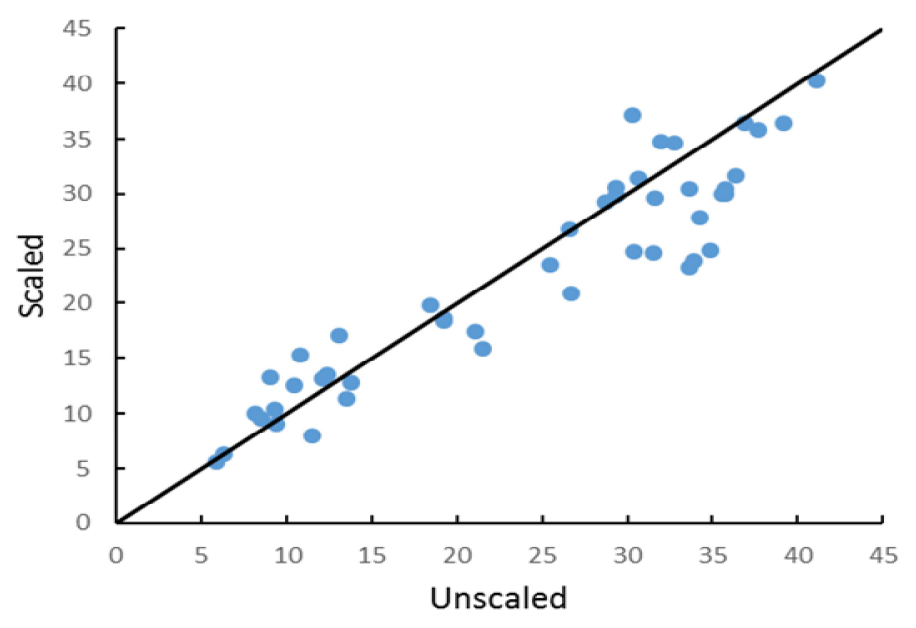

Figure 5: Earthquake duration comparison before and after adjustment

\section{Duration effect}

In this study, significant duration was used to measure earthquake duration. Obtained results show that duration has no significant effect on maximum response measures but other ones are closely correlated to duration and increase with increase in duration.

In the following, at first results for maximum response measures shall be given, includes peak member end rotation for beam and column, peak inter-story drift and peak roof drift.

Fig. 6 shows duration effect on peak column end rotation. As it is clear, there is no increase in peak column rotation with increase in duration. In addition, Fig.7 show this one for beam. 


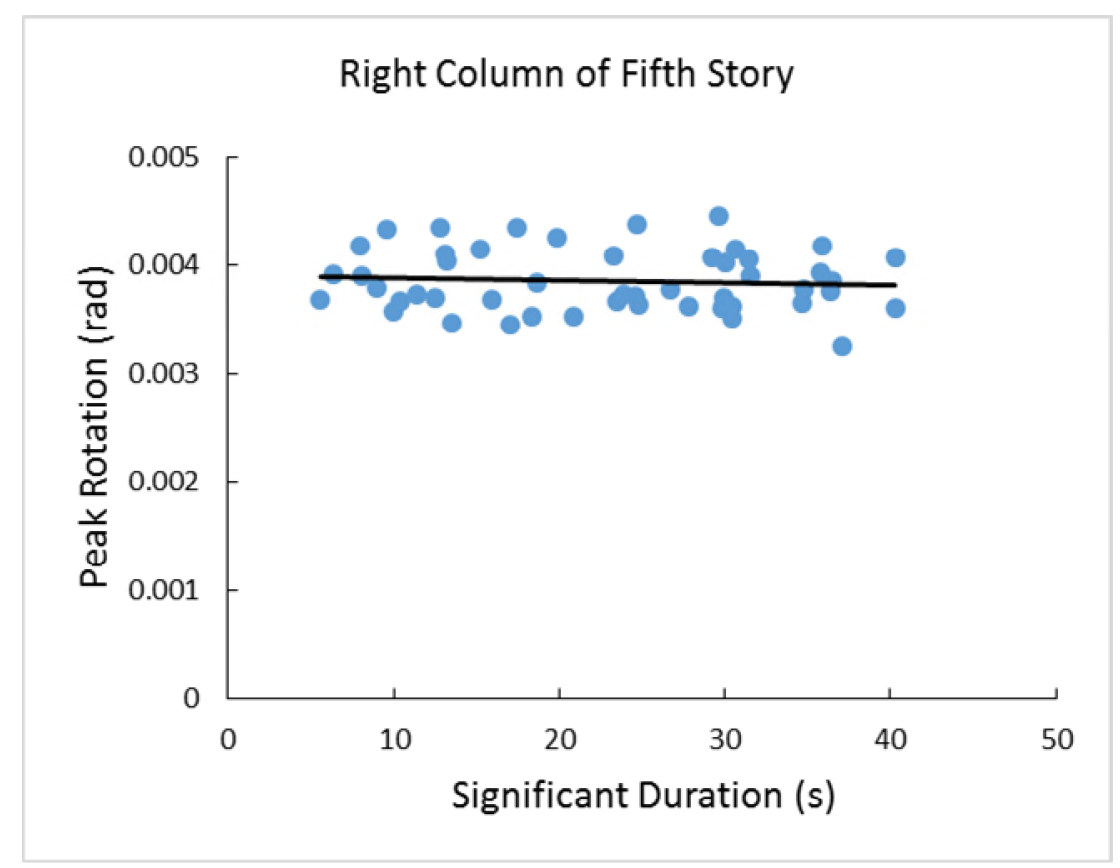

Figure 6: Peak column rotation for fifth story vs. earthquake duration

Other maximum measures have been examined are peak roof drift and peak inter-story drift for different stories. In Fig. 8 can be observed that increase in duration causes a slight increase in peak roof drift. From five to forty seconds peak roof drift increment is about $12 \%$. Fig. 9 shows inter-story drift for all the stories. As is clear, there is no significant correlation between duration and inter-story drift but it seems that the stories with higher drift or with higher level of inelasticity affect with duration and positive slope in trendline is obvious. For example, fifth story drift for an earthquake with significant duration equal to forty shows about $16 \%$ increase rather than an earthquake with significant duration equal to five. By the way, this value for first story drift is equal to zero.

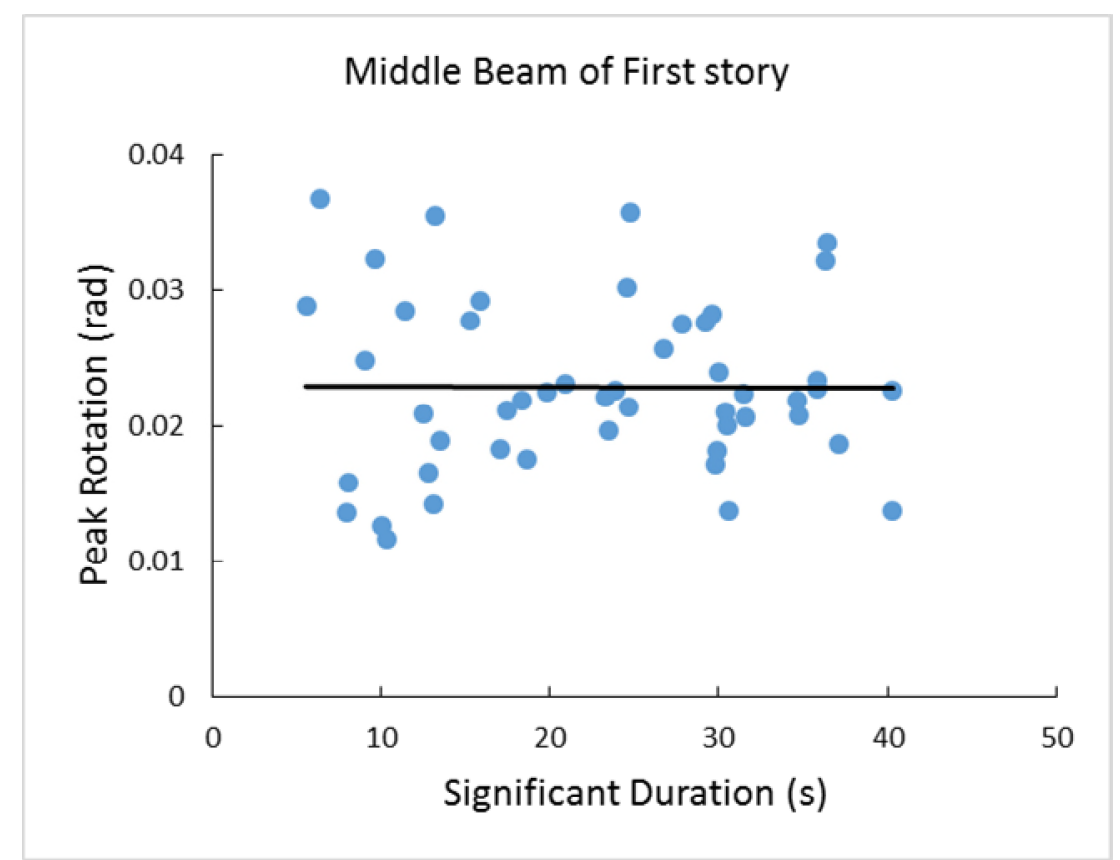

Figure 7: Peak beam rotation for first story vs. earthquake duration 
Bulletin de la Société Royale de Liège, Vol. 86, special edition, 2017, p. 234 - 247

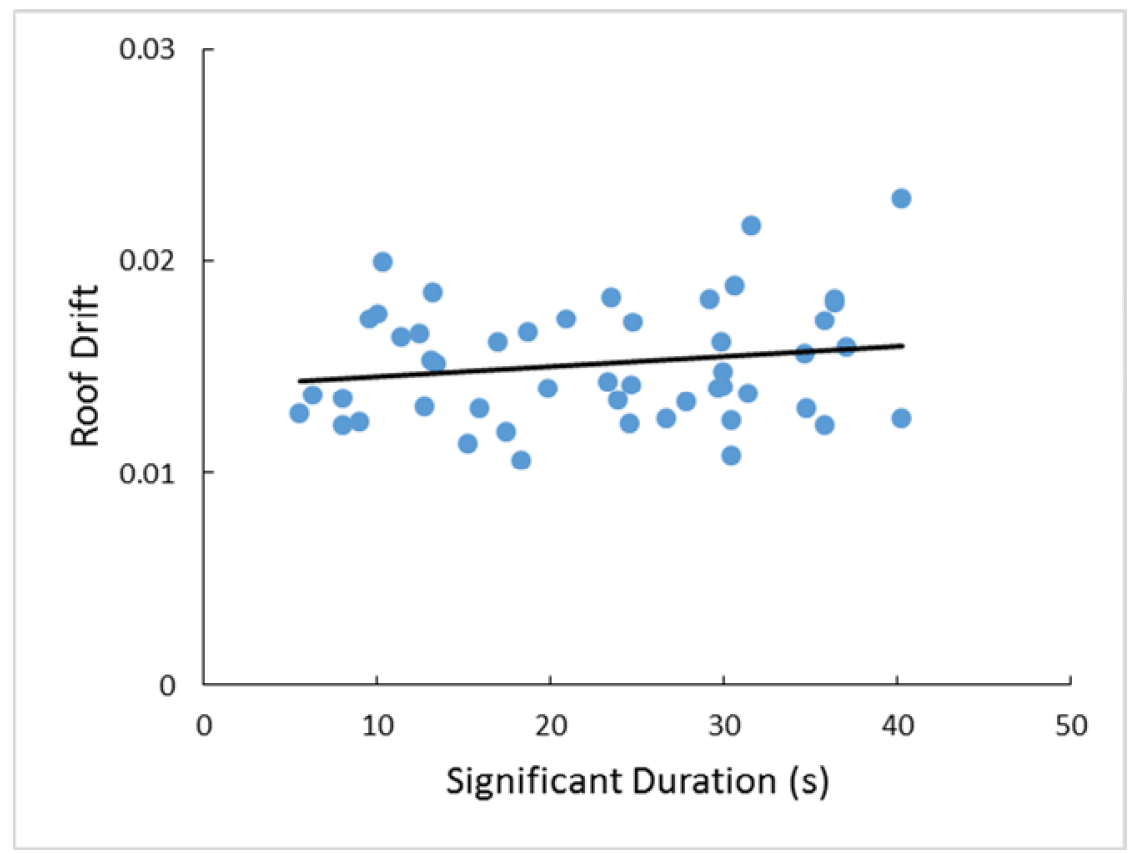

Figure 8: Roof drift vs. earthquake duration

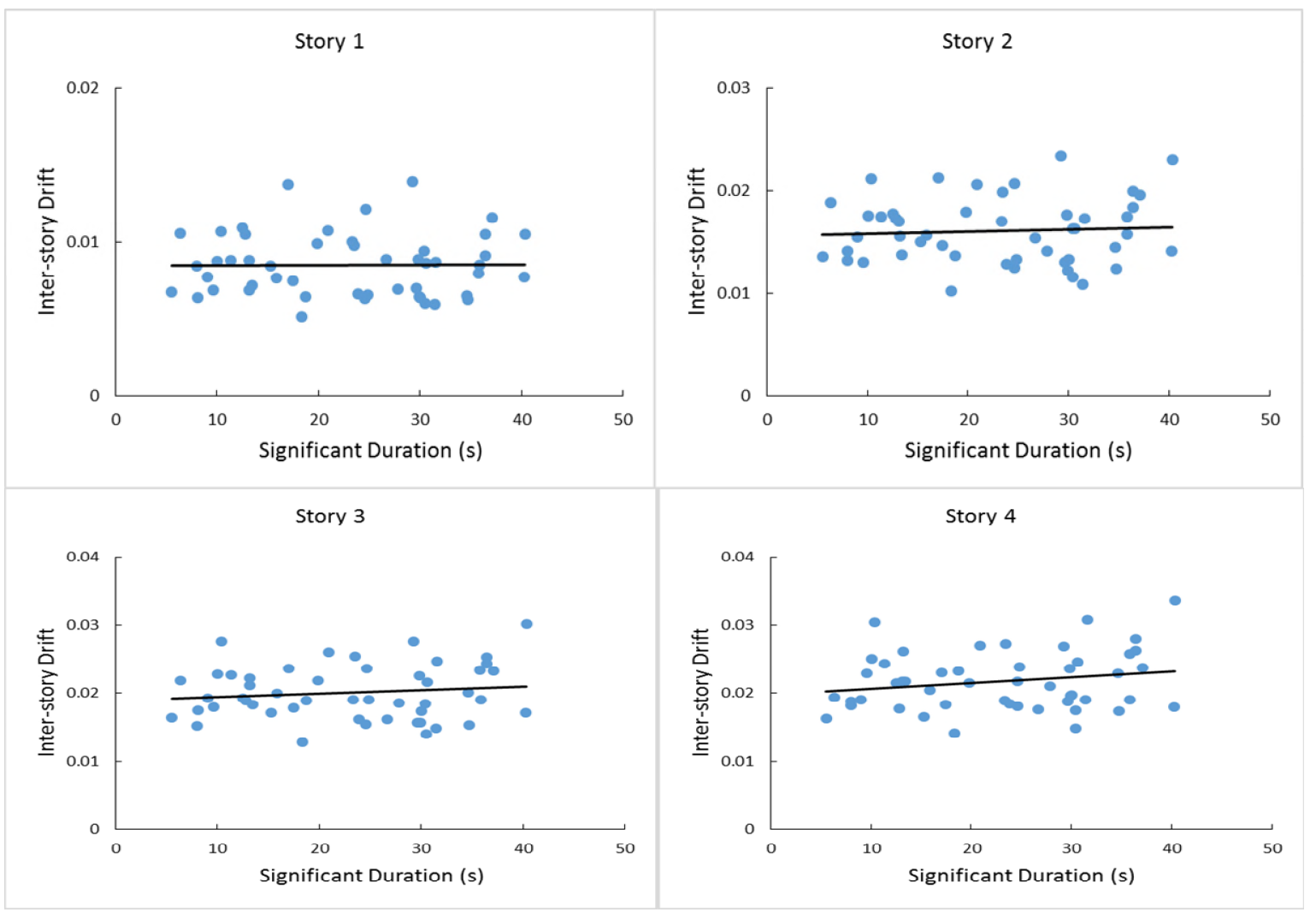




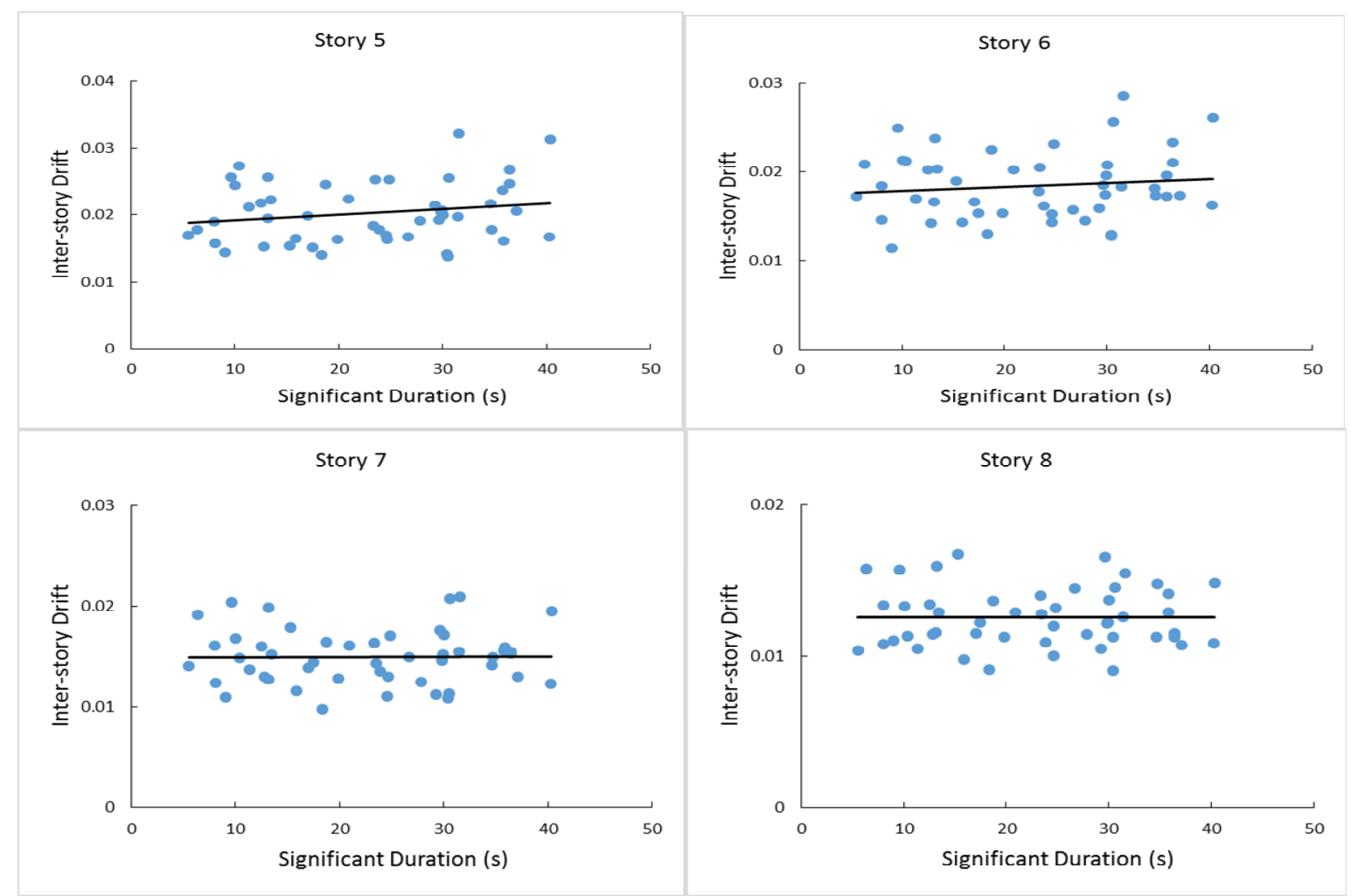

Figure 9: Inter-story drift vs. earthquake duration for different stories

Member rotational fatigue $\left(\mathrm{DI}_{\mathrm{f}}\right)$ is calculated with proposed method in ASTM [14]. Cumulative damage is calculated using Miner's Linear Damage Accumulation [10]:

$$
D I_{f}=\sum_{i=1}^{n} \frac{1}{a} \theta_{i}^{k}
$$

In which $a$ is fatigue constant, $k$ is exponent constant, $\theta_{i}$ is amplitude of $i$ th rotation and $n$ is number of all cycles. $k=3.86$ results in Yamada experimental test [15] for concrete column with demand capacity ratio of axial load equal to $1 / 3$. Fatigue constant is set in the way that damage measure in ultimate monotonic rotation is equal to unity. As proposed by Park and Pauly [16] and Paulay and Priestley [17] fatigue constant value is calculated from analysis of section. Effect of dead and live loads should be incorporated in the analysis.

Effect of duration on fatigue damage can be seen in Fig. 10. As shown, increment in fatigue damage measure correspond to increasing duration with relatively large slope. 


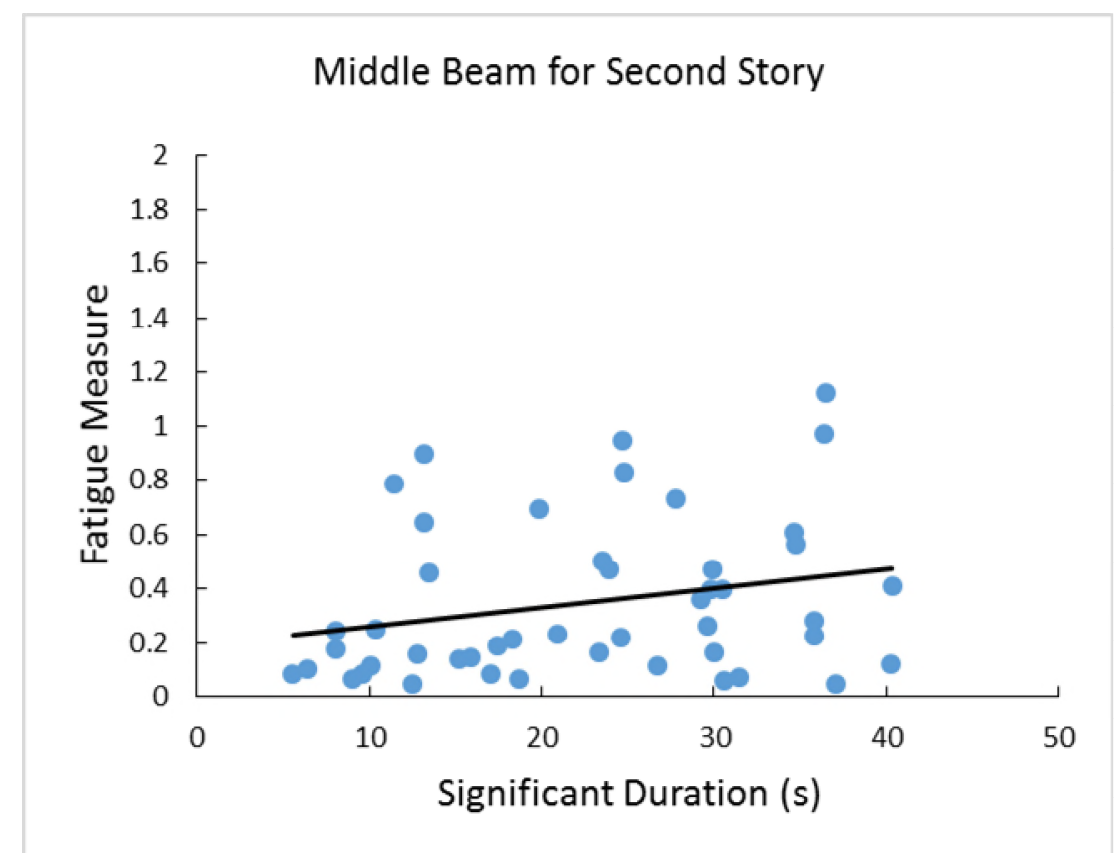

Figure 10: Effect of earthquake duration on fatigue measure

Damage measure of member absorbed hysteretic energy is another measure have been assessed. Absorbed hysteretic energy for member end is calculated by integrating the area enclosed by moment-rotation hysteresis curve. In Fig. 11, this damage measure has been assessed. This measure is correlated to duration, too. The amount of increase in absorbed hysteretic energy by the member is about $35 \%$ for an earthquake having significant duration equal to forty seconds in comparison to an earthquake with significant duration equal to five seconds.

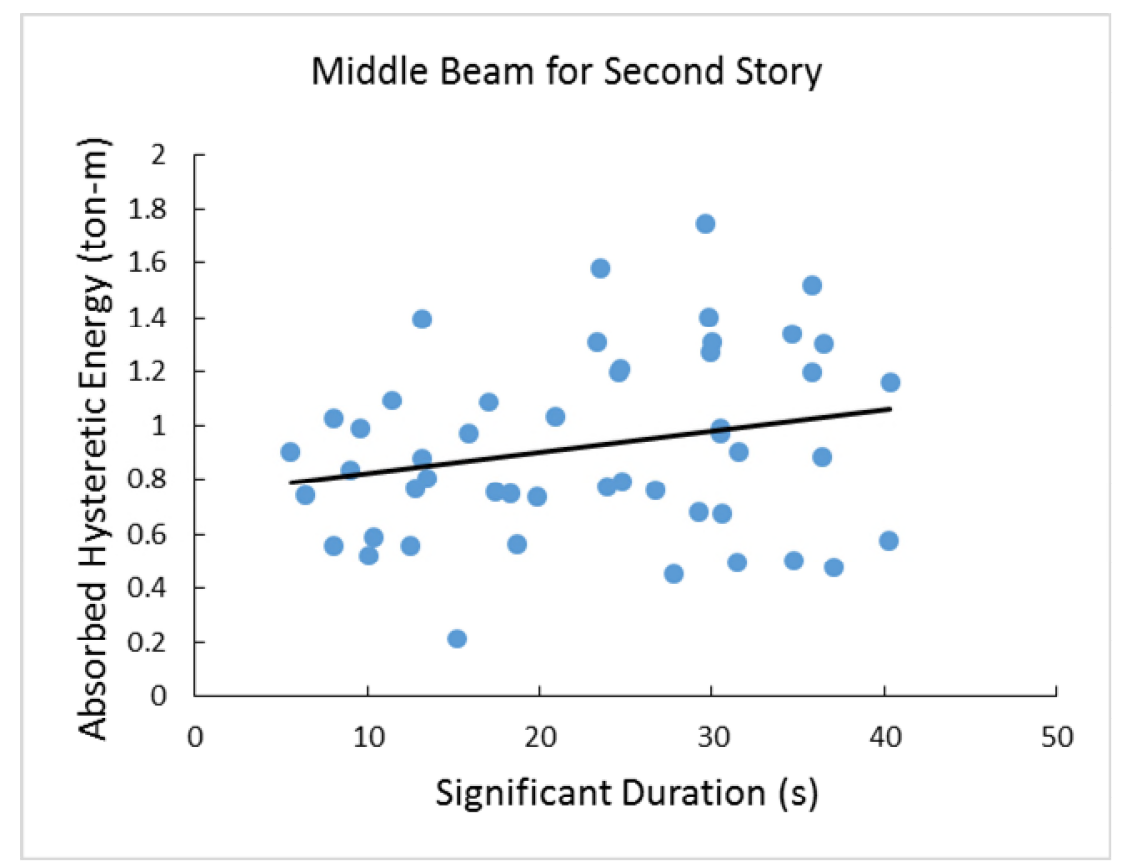

Figure 11: Absorbed hysteretic energy vs. earthquake duration 
It should be mentioned that current seismic codes use maximum response measures for evaluating the damages in the structure but according to the researches conducted, using measures considering internal energy to the members estimates structural damages more accurately. For this reason, in the following, one of the most popular combination measures i.e. Park and Ang measure is assessed.

Park and Ang measure [18] for the member $\left(D_{\text {pad }}\right)$ is defined by combination of absorbed hysteretic energy and peak rotation:

$$
D_{p a \theta}=\frac{\theta_{M}}{\theta_{u}}+\frac{\beta}{M_{y} \theta_{y}} \int M d \theta
$$

Where $\theta_{M}$ and $\theta_{u}$ are peak member rotation during the time-history analysis and ultimate member rotational capacity, respectively, $\beta$ is an empirical factor to consider effect of cyclic loads is set to 0.15 as proposed by Cosenza and Manfredi [19], $\int M d \theta$ is absorbed hysteretic energy finally $M_{y}$ and $\theta_{y}$ is yield moment and rotation. [10]

In Fig. 12, Park and Ang damage measure is examined. This measure like rotational fatigue and absorbed hysteretic measure is correlated to duration. The amount of increase in damage measure for an earthquake having significant duration equal to forty seconds rather than an earthquake with significant duration equal to five seconds is about $27 \%$.

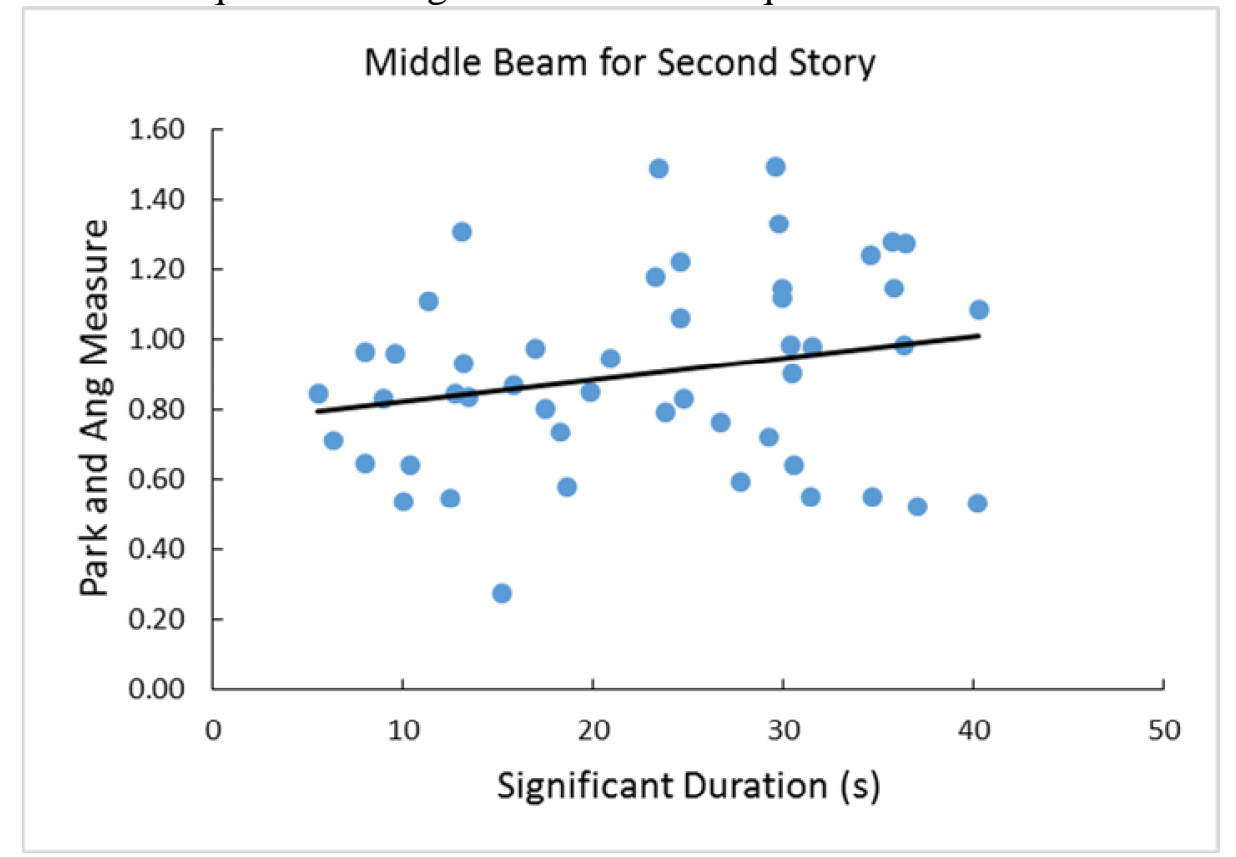

Figure 12: Park and Ang Damage vs. earthquake duration

\section{Conclusions}

Using accelerograms having matched records enables researchers to explore different characteristics related to the earthquake, like duration. Whereas, using natural records (without adjustment) that have variable response spectrum is impossible for determining the effect of a specific characteristic like earthquake duration. For this reason, most researchers use different methods to adjust and scale records in order to separate duration 
effect of the other characteristics. In the analyses have been done on an 8-story building it was cleared that earthquake duration has no effect on maximum response measures like peak member end rotation. However, there is partial correlation in the other measures in this group like inter-story drift and roof drift. Mentioned measures are design basis in current seismic codes. Exploring other damage measures like rotational fatigue, member absorbed hysteretic energy and Park and Ang damage shows meaningful correlation between earthquake duration and structure damages. The more earthquake duration is the more structural damages observed. It is noteworthy to say that providing duration entry field to the seismic codes. It helps engineers to have more accurate estimate of structural damages and thus provide conditions to minimize damages caused by the earthquake.

\section{References}

1. Chai YH, Fajfar P. (2000), "A procedure for estimating input spectra for seismic design,” J Earthquake Eng.; 4(4):539-61.

2. Kunnath SK, Chai YH. (2004), "Cumulative damage-based inelastic cyclic demand spectrum,” Earthquake Eng. Struct Dyn; 33:499-520.

3. Iervolino I, Manfredi G. (2006), "Cosenza E. Ground motion duration effects on nonlinear seismic response,” Earthquake Eng. Struct Dyn; 35(1):21-36.

4. Shome N, Cornell AC, Bazzurro P. (1998), "Carballo JE. Earthquakes, records and non-linear responses," Earthquake Spectra; 14(3): 469-500.

5. Bommer JJ, Magenes G, Hancock J, Penazzo P. (2004), "The influence of strongmotion duration on the seismic response of masonry structures," Bull Earthquake Eng.; 2(1):1-26.

6. BHRC (Building and Housing Research Center). 2014. Iranian Code of Practice for Seismic Resistant Design of Buildings. Standard No. 2800, 4rd edn. BHRC: Tehran.

7. Computers and Structures, Inc., "Perform 3D," 5 ed, 2011, Nonlinear Analysis and Performance Assessment for 3-D Structures.

8. ASCE 41. "Seismic Evaluation and Retrofit of Existing Buildings." (2013).

9. Fajfar P. (1992), "Equivalent ductility factors, taking into account low-cycle fatigue," Earthquake Eng. Struct Dynamic; 21:837-48.

10. Hou H. and Qu B. (2015), "Duration effect of spectrally matched ground motions on seismic demands of elastic perfectly plastic SDOFS," Engineering Structures; vol. 90, pp. 48-60.

11. Seismosoft, "SeismoMatch," 2.1.2 ed, 2013, spectral matching program.

12. Jonathan Hancock, Julian J. Bommer. (2007), "Using spectral matched records to explore the influence of strong-motion duration on inelastic structural response," Soil Dynamics and Earthquake Engineering; 291 - 299.

13. Bommer JJ, Martinez-Pereira A. (1999), "The effective duration of earthquake strong motion," J Earthquake Eng. 3(2):127-72.

14. ASTM. (1985), "Cycle counting in fatigue analysis," Annual Book of ASTM Standards, 03.01 issue E1049-85, p. 836-48. 
15. Yamada, M. (1992), "Practical ductility assurance of structures for aseismic design," Earthquake Engineer; p. 3409.

16. Park, R. and Paulay T. (1975), “ Reinforced Concrete Structures,” New York; John Wiley and Sons, p. 75-76.

17. Priestley M. and Paulay T. (1992), "Seismic design of reinforced concrete and masonry buildings," New York; John Wiley \& Sons, Inc.

18. Park, Y.-J. and Ang A.H.-S. (1985), "Mechanistic seismic damage model for reinforced concrete" Journal of structural engineering; 111(4): p. 722-739.

19. Cosenza E. and Manfredi G. (1998), "A seismic design method including damage effect," in 11th European Conference on Earthquake Engineering. 